\title{
The Paradigmatic Evolution of U.S. Television and the Emergence of Internet-Distributed Television
}

\section{La evolución paradigmática de la televisión de EE.UU. y la aparición de la televisión distribuída por Internet}

\author{
Amanda D. Lotz \\ Professor in the Departments of Communication \\ Studies and Screen Arts and Cultures \\ (University of Michigan)
}

- Guest paper -

Reception date: 10 July 2016

To cite this article: Lotz, A. D. (2016): The Paradigmatic Evolution of U.S. Television and the Emergence of Internet-Distributed Television, Icono 14, volumen 14 (2), pp. 122-142. doi: 10.7195/ri14.v14i1.993 
MONOGRÁFICO

\section{Abstract}

Television industries around the world have weathered profound change as technologies advanced and services developed to allow internet-distributed television to compete alongside broadcast and cable-distributed television. This article, drawn from the context of the U.S., explores the emergence of internet-distributed television as a mechanism that provides the affordance of nonlinear distribution. It assesses the preliminary organization of internet-distributed television by portals and explores the similarities and differences between portals and networks/channels with an eye toward conceptualizing emerging business practices and strategies.

\section{Key Words}

Television - Internet-distributed - Netflix - Subscriber-funded - Portals - Affordance Nonlinear

\section{Resumen}

Las industrias de televisión de todo el mundo han resistido al profundo cambio que las tecnologías avanzadas y los servicios desarrollados que facilitan la distribución de television por Internet suponen como competencia de la distribución de televisión abierta y por cable. Este artículo, partiendo del contexto de los Estados Unidos, explora la aparición de la televisión distribuída por internet como un mecanismo que habilita y ofrece la distribución no lineal. Evalúa la organización inicial de la televisión distribuida por internet a través del análisis de portales y explora las similitudes y diferencias entre estos portales y las redes y canales, poniendo el foco en la conceptualización de las prácticas y estrategias de negocio emergentes.

\section{Palabras clave}

Television - Distribución por internet - Netflix - Abonados - Portales - Enactividad - No lineal 


\section{Introduction}

A decade ago, the question of "what is television" was a popular topic of conversation among television scholars. The uncertainty was fueled by the emergence of non-television screens-first, mainly desktop and laptop computers-that were able to show short bits of video that had previously only been viewable on a television screen. Similarly, a device initially known as a "video iPod" that was capable of downloading and screening television series emerged in 2005. Though of nascent use ten years ago, such a device challenged expectations of how television was viewed and stoked anticipation of coming radical change. Television had long been defined as a domestic medium and characterized by its reception of a linear schedule. Such new screen devices defied the established protocols of television in ways that caused many to speculate about whether television possessed defining attributes, and if so, what they were.

At that time, adjustments in the broader television industry were still most preliminary, but it was clear that the U.S. television industry was on the cusp of radical disruption. The main source of the disruption was digitization, which by that point had substantially affected the businesses and audience practices of the music recording and newspaper industries. To be clear, there was no doubt internet distribution would produce sizable change for television as well, but it was difficult to anticipate the corresponding shifts in production, financing, and other industrial practices for broadcast and cable distributed television. This disruption remains in progress, maybe even in early stages in 2016, but much more insight into the implications of this new distribution technology is now available.

\section{New technologies for viewing television}

As television slowly became unmoored from the norms that governed its industrial and audience practices in the early 2000s, significant anxiety of what would become of television emanated from uncertainty of its defining characteristics. Television scholar Lynn Spigel valuably offered a multifaceted definition of television in 2004 and distinguished television as characterized by "technologies, industrial formations, government policies, and practices of looking" (Spigel, 2004, 2). 
Such theorization importantly acknowledged the multiple factors, historical context, and socially constituted nature of television, rather than limiting it to its technical attributes as a screen technology. Importantly, Spigel included the mechanisms for making and distributing its programming, its program organization, audience expectations of that programming, and their behaviors of engagement as constitutive of the medium. Though not identified as such, these are the "protocols," in Lisa Gitelman's terms, that have defined television every bit as much as its screen (Gitelman, 2008, 5). New technologies for viewing television emerged in the first decade of the twenty-first century, but it remained unclear how the protocols for these new technologies would diverge from those already established.

When I wrote of a "post-network era" in 2007, I did so because it was clear that substantial change was coming, but only the roughest contours of that change could be discerned (Lotz, 2007). I have come to somewhat regret the term chosen, though stand behind the general assertion intended. My own thinking conflated two phenomena that I have only recently been able to disarticulate with the benefit of hindsight and new research: textual innovation introduced by original, scripted cable series and the technological capacity for nonlinear distribution.

The choice of "post-network" rather than "post-channel" grew from the shifting dynamic between broadcast networks and cable channels in the U.S. market in the first decade of the twenty-first century. That decade produced remarkable adjustments in television programming - particularly in scripted series-as a result of U.S. cable channels' innovation in this period. Though it is difficult to remember some twenty years removed, the first successful original, scripted, cable dramas-HBO's OZ and USA's La Femme Nikita-did not debut until 1997. HB0-as a subscriber-funded service had many advantages and quickly established unimagined possibilities for U.S. television in the remainder of the decade. It required five years for ad-supported cable to mount another success with The Shield and Monk, both in 2002, and it was five more years until it matched HBO's creative accomplishment with Mad Men in 2007. These shows are emblematic of a heady period of change in U.S. television in which industrial conditions encouraged creative innovation to an extent that had been difficult since the first years of the medium. 
Although a new series from a cable channel is of little novelty by 2016, this was not the case in the early 2000s. Many cable channels created programs markedly different from the fare typically offered by broadcast networks in this decade, and this shift was disorienting. The sense of programming innovation inadvertently mixed with the broader cultural awareness of the ways internet distribution was disrupting the recorded music and newspaper industries. Matters of internet speeds, the size of digital files, and state of compression technologies helped delay internet distribution of television and film. Notably, there were many-mostly forgotten-experiments with internet-distributed television in these years that likewise hinted of profound coming change, although viewing of internet-distributed video before 2010 was mostly an early adopter phenomenon. The television studios that owned the rights to series were afraid of losing control of intellectual property and disrupting business models. They consequently allowed very little content that most would recognize as "television" to circulate.

It is difficult to explain the zeitgeist of the first decade of the twenty-first century. Creative risk-taking, spurred by changing competitive conditions and enabled by business models less reliant on advertising - some even devoid of advertising, drove programming innovation among cable channels. But that industrial context was largely subsumed by the sense of profound possibility and rupture that could emerge at any moment as a result of what was mythologized as the coming of "new media."

My terminological choice of "post-network era" was influenced by that zeitgeist. While I never believed or intended to suggest that broadcast networks would disappear-as in the post-network era was to be an era after broadcast networks-I should have chosen terminology that better acknowledged that the defining shift would be from linear to nonlinear distributed television. A better term would have implicated linear-organized cable channels as well, so perhaps "post-channel" would have been clearer.

Yet even beyond this, I am now troubled by the conceptual limits of choosing to organize television's transition itself in linear terms among eras when considerable overlap and coterminous operation will likely proceed for decades, if not 
indefinitely. I imagined the time frames of the network era, multichannel transition, and post-network era as rough periodizations without exact starting and end points, but even such a flexible scheme inevitably obscured overlap. Though norms of the network era were clearly "dominant" in the past, it is less clear in 2016 how to assess or determine dominance, and it may be more beneficial to develop frameworks in which a multiplicity of norms coexist.

Recent research has sent me back to the mid-1990s with the aim of uncovering the chronological story of change, the story of what happened to U.S. television over the last two decades. Although I have written extensively about this period, even I lacked a conceptual frame for the process of what transpired. Certainly anyone even half interested in television could easily tick off a number of relevant milestones-The Sopranos, Mad Men, Netflix-but little understanding of how these milestones came to be exists. Excavating the developments of the last twenty years may be a history of the very recent past, but it is a history nevertheless, and seeking to uncover the story of transition is a different intellectual task than attempting to make sense of developments as they occur.

With the critical distance of some twenty years, it became clear that two different disruptions occurred (Lotz, forthcoming). First, as noted above, U.S. cable channels began producing original, scripted series in the late 1990s. This strategy emerged at this time because of a shift in the competitive landscape. In the late 1990s, the cable service providers - which are companies distinct from those involved in creating content, the cable channels-were rebuilding their infrastructure. Although a very few may have anticipated the importance of this technological rebuild in terms of internet-distributed television, the focus in the moment was expanding cable video service. The profound change in cable programming resulted from the transition to digital cable systems that expanded competition from roughly thirty channels to three hundred.

The original series that emerge-mostly just after the start of the twenty-first century - led to a reimagining of television storytelling among viewers, but attention to the programming largely masked consideration of the sizable shifts in business norms behind the scenes. Original, scripted cable series developed because 
of a shift in business and marketing strategies. On the business front, although many continued to discuss "competition" between cable channels and broadcast networks, by 2000, this was a false competition. Considerable conglomeration throughout the late 1990s resulted in most cable channels and broadcast networks having common owners so that broadcast networks and cable channels had become sibling divisions of parent corporations. At the same time deregulation allowed for these new massive media conglomerates, rules that had forced broadcast networks to buy shows from separately-owned studios expired (Financial Interest and Syndication rules). The result was a steady shift from the U.S. television business as one of distribution and advertiser-support, to a complex matrix of revenue delivered from advertising, intellectual property licensing, and subscriber fees.

The shift in marketing strategy also related to the changing competitive environment. In an era of analog cable systems, the limited competition among a few dozen cable channels had made it possible for a channel to survive and even thrive merely by offering old programs previously aired by broadcast networks. As digital cable expanded the competition to include hundreds of channels, it became more challenging for a channel offering such programs to stand out. Moreover, cable channel revenue derived from both affiliate fees paid by cable service providers and advertising in roughly equal parts. The growing competition made difficult expanding audience size-and thus advertising. Increasing fees paid by cable systems afforded another strategy for revenue growth, but negotiating higher rates required channels to offer programming not otherwise available and with some distinction. Creating original, scripted series offered both distinction and an opportunity to more clearly brand a channel's identity and stand out amidst the quickly expanding competition.

The creation of original, scripted cable series thus disrupted industrial norms and practices over the course of a decade, but well before internet-distributed television confronted the industry. Rather than the schematic of change organized as a network era, multichannel transition, and post-network era, this process of transition is better conceptualized as shifting paradigms. Using paradigm in a Kuhnian sense to encompass standard practices and behaviors as well as a modes of thinking, incorporates a valuable breadth of factors (Kuhn, 1962). It allows the conceptualization of 
a "broadcast paradigm," composed not only of industrial formations and audiences practices but also of how industry and audiences conceive of and understand television. Parallel to the impulse of Spigel's multifaceted definition of television as encompassing technologies, industrial formations, government policies, and practices of looking, it is not simply the practices of a network era, but the pervasive way of thinking captured by a broadcast paradigm that reinforces hegemonic norms.

As a result of the development of original, scripted cable series, by the early 2000s, a new paradigm began to compete with the broadcast paradigm, one I identify as a broadcast/cable paradigm. In the same way that Raymond Williams identifies stages of emergent, dominant, and residual cultural formations, so too can these paradigms be set in relation so that multiple paradigms can exist coterminously (Williams, 1977, 121-2). Throughout the first decade of the twenty-first century, a broadcast/cable paradigm "emerged" and gradually became dominant by 2010. Importantly, the broadcast paradigm did not expire, rather the presumptive supremacy of its practices and mode of operation as the only mechanism for U.S. commercial television incorporated those of cable as an equally legitimate form of television. As the blended name suggests, the broadcast/cable paradigm is not characterized by considerable change. Many norms of the broadcast paradigm persisted, but those of cable came to coexist with and be identified as every bit as valid and characteristic of "television" as those of broadcasting. The significance of this adjustment only becomes clear if one remembers the lowly status afforded to cable programming through the mid 1990s. Cable channels and their programming evolved from being widely regarded as of lesser quality and lower cultural capital to being a central component of the television industry.

Importantly, the emergence of a broadcast/cable paradigm was not only a matter of programming, but also of various industrial practices that broadcast networks adopted from cable channels, particularly the reliance on subscriber funding. Beginning in 2007, the broadcast networks negotiated for retransmission fees from cable service providers that functioned much like the affiliate fees paid to cable channels. This substantial new revenue stream-along with the vertical integration opportunities enabled by the elimination of the Financial Interest and Syndication rules-adjusted broadcast network business practices significantly. 
Notably, all of these adjustments transpired before distribution of video using internet protocol technologies became substantial. The arrival of television distributed over the internet-a development that becomes a clear phenomenon in the U.S. in 2010-is the second disruption in this twenty-year evolution. It required a handful more years to understand the profound nature of this adjustment that remains very much in process. Nevertheless, it is possible to conceptualize the extent and nature of the disruption it has thus far wrought.

First, to clarify terms-I designate internet-distributed video to reference a distribution protocol distinct from the transmission of broadcast waves or traditional cable/satellite video distribution. Internet-distributed video encompasses delivery by wired internet service or cellular data delivered to a phone or other wireless device. At a technical level, it is defined by distribution using internet protocols that disassemble data into packets for efficient transmission and then reassemble it.

I take such pains to emphasize internet distribution technology that contrasts with broadcast waves, cable, or satellite as distribution technologies because distribution technology is so crucial to conceptualizing what has happened to television and why. As mechanisms of distribution, broadcast, cable, and satellite had a defining technological affordance-namely the capacity to widely transmit a single message. This technological ability is an important affordance, but these distribution mechanisms were likewise limited by the scarcity of being able to transmit only one signal at a time. This limitation encouraged the development of many of the protocols associated with television. The scarcity of a single, one-way signal necessitated organization of a schedule and focused industrial practices on constructing a schedule and developing entities such as stations, networks, and channels to perform this role. Importantly, in the U.S., regulatory regimes derive from distribution technologies. In addition to being governed by a different regulatory regime, cable developed a different business model than broadcast, and both distinctions discrepantly circumscribed broadcast and cable distributed television despite other commonalities.

Internet distribution, in contrast, is not a technology best suited to mass distribution of a single message. The compression, transmission, and caching technologies developed by 2010 allowed for a very different experience of video than 
available by broadcast, cable, or earlier internet distribution. Rather than the orderly schedule that delivers certain programs to all audiences at pre-established times, internet distribution has the capacity to send content at a viewer's request in a way that allows viewers uncommon control over pacing and choice of content in comparison with broadcast and cable technologies ${ }^{1 .}$

Of course, video was distributed over the internet before 2010, but this is the year that content characteristic of "television" became available and began to be experienced in the U.S. (notably several years after the launch of BBC's iPlayer). The technological capacity to distribute video alone was inadequate to introduce widespread change in viewing practices, but in 2010, HBO Go and Netflix introduced a seamless, high-quality experience of television distributed over the internet. Moreover, 2010 marked the introduction of tablets as a viewing technology that helped disturb the binary thinking of screens as either those of televisions or computers that had dominated thinking to date. Smartphones-first introduced in 2007, but largely an early adopter phenomenon until 2010-ultimately became the more pervasive handheld screen technology, but both technologies proved important to the emergence of television distributed over the internet.

Rather than a post-network era then, a paradigm of television distributed over the internet became emergent in 2010 and remains ascendant in 2016. A range of developments throughout 2015 suggested further growth in internet-distributed television, but it remains distinct from broadcast and cable-hence no likelihood of a merged broadcast/cable/internet paradigm. Internet-distributed television may simply co-exist with the broadcast/cable paradigm instead of coming to supplant its dominance.

Importantly, this framework of paradigms better allows for conceptualizing the existence of a multiplicity of distribution technologies and related norms-as is now the case. This framework assumes media to be distinct from their distribution technology, and paradigms are not defined by technology and practice alone, but also encompass ways of thinking about television-whether in terms of how industrial players predominantly understand the operation of the industry or how audiences conceive of viewing practices and what they expect when watching television. The technological affordances and limitations of broadcast, cable, and 
satellite transmission produced many practices and protocols that have long been assumed as norms of television, but they were not innate to television at all. They were characteristic of television as distributed by these technologies.

Moments of ruptured paradigms of media operation and use are not without precedent. The 1940s provides a valuable point of comparison. The paradigm of radio shifted considerably upon the emergence of television-although in this case distribution technology remained constant. Likewise, a conceptual framework of paradigms makes it possible to imagine how a reconfigured broadcast paradigm might reemerge radically remade from previous norms if television broadcasting considerably adjusts - as radio once did-in response to a competitive landscape that includes a competitor with different affordances.

\section{What is Internet-Distributed Television?}

It was noteworthy that the device then-called a "video iPod" was soon known simply as "iPod." These shifting naming conventions reveal the norms of the technological spheres they disrupt. Prior to the development of the video iPod, an iPod was an audio-only device. It had a screen, but it was used to view contents and playlists and aid the manipulation of audio tracks held on the device. As it became customary for portable devices to have screens capable of playing video, the marker of "video" fell from use, just as the technology preliminarily identified as a "digital camera" has simply become a "camera."

So too, then, will "internet-distributed" likely disappear as a distinct categorization of television in time. This parallels the initial distinction in the U.S. market between broadcast and cable television that has become completely invisible to those who never knew a world without cable. Of course, significant industrial distinctions nevertheless remain that characterize and allow for meaningful differences among these distribution technologies. Markedly different governmental policies discrepantly regulate broadcast and cable television, and their business models vary, but have grown more similar. Though these distinctions are often invisible to audiences, accounting for them remains critical for academic conceptualization. 
An important preliminary focus for scholars conceptualizing internet-distributed television involves identifying the consistencies and deviations among known strategies and practices of broadcast, cable, and satellite-distributed television relative to those characteristic of internet-distributed television. At this still-preliminary point, analyses tend to over-ascribe determinant power to technology with limited acknowledgement of the significant variation among strategies and business models among various internet-distributed competitors.

To begin with technological differences, Internet-distribution does not require the organization of television into a linear schedule. It is difficult to underestimate the implications of this difference on the industrial practices available to internet-distributed television in comparison with those previously common. As French cultural industries scholars such as Bernard Miége identified, the central function of broadcast industries is the production of a schedule (Miége, 1989). The scarcity allowing only the transmission of a single piece of content at an appointed time encouraged many other industrial and audiences practices that have come to be regarded as characteristic of the medium of television. Many other "norms" of television become less viable or seem less "natural" once the requirement of linear distribution is eliminated. This difference in affordances allows-perhaps requires - the distinct practices of internet-distributed television that are emerging.

Notably, various digital technologies also introduced nonlinear viewing capability earlier in the 2000s-whether DVR technology or video-on-demand functionality made available from cable operators. The fact that devices such as the DVR mirror the affordances of internet distribution makes developing elegant conceptual frames difficult because both enable the same "ways of looking" that are distinct from previous norms. Digital cable and satellite services can now mirror nonlinear affordances with recording devices in viewers' homes or at the headend facility, some of which even use internet protocol ${ }^{2}$. Throughout the early 2000s, cable service providers added functionality such as the ability to record, rewind, and pause programming, although in some cases faced legal action from content rights' holders for doing so. By 2013, cable service providers achieved agreements with content owners (studios) to allow a substantial amount of programming on demand. This availability made distinguishing cable and internet distribution 
difficult from a technological standpoint-and was further confounded by the fact that cable service providers are also the dominant source of home internet service in the U.S. Importantly, cable on demand and internet distributed television maintained very different industrial practices that support the distinction made here-at least as of 2016.

It seems likely that this conceptual frame relying on the variant affordances of different distribution technologies to explain divergent industrial and audience practices in a common medium of television may need adjusted in as few as five years time, but today, this provides a productive strategy for conceptualizing the distinctions and continuities of television distributed over the internet. To again invoke Spigel's multifaceted definition of television, broadcast and cable remained defined by their linear schedule in 2016 in terms of industrial formations and practices of looking despite the availability of other affordances, at least for cable distribution. I do not mean to disregard the important nonlinear functionality introduced by DVRs and cable on-demand access in emphasizing nonlinearity as a technological attribute of internet-distributed television, but rather to underscore how nonlinear is characteristic of the operation of most internet-distributed sources. Government regulation of internet-distributed television remains uncertain and it does not yet have a defined regulatory regime.

Before moving into deeper conceptualization of internet-distributed television, it is also crucial to acknowledge consistencies of television among these distribution technologies. Contrary to many expectations of "new media" that circulated in the late 1990s and early twenty-first century, internet-distributed television is not a new medium, but the medium of television distributed through a different technology. The capacity of internet-distribution technology alone proved of minimal influence until services emerged to make this distribution technology useful. Thus the industrial formations of companies distributing television over the internet and their emerging protocols are an important component of conceptualizing this form of television.

Just as networks and channels have served as the organizing mechanism for their respective distribution technologies, so to has internet-distributed television required such a mechanism. I prefer the term "portal" to describe entities such 
as Netflix, Hulu, HBO Now, YouTube, and the many others that have emerged to coordinate access to internet-distributed television. Others have termed these as platforms or apps; all of these terms carry with them wide-ranging and complicated uses. Portal first emerged in relation to computing to describe a website or service that provided internet service, then to websites or services that provided access to a variety of content, for example, AOL as an internet portal (Oxford English Dictionary). Portal has otherwise fallen from use, freeing it for this use that draws on the notion of a gateway to video content. Platform continues to be used extensively as computing systems (Bogost \& Montfort, 2009) or as a set of interfaces and tools (Facebook platform), while apps describe too broad an array of programs or software. Platform and app can also connote viewing on particular devices, and this theorization of portal seeks to be device agnostic. The entities distinguished as portals here provide access to a wide range of content and the thirteenth-century definition of the term emphasizes their function as a gateway, in this case to a library of television programs.

Notably, neither channel nor network has been used to describe these entities, although portals serve similar functions. The central task of channels, networks, and portals is organization. The scarcity of distributing only one bit of content at a time necessarily shifts much of the work of channels and networks to ordering that content into a schedule. The portal too organizes, though its activity may be more precisely understood as the curation or cultivation of a library. From a business perspective, the most substantive difference between channels or networks and portals results from the disparity between producing a schedule versus producing a library.

Importantly, there are many different strategies through which the business of creating and maintaining a library might be pursued, but the limited cases of commercial library curation-whether within media or in the sale of other goods-provide little foundation from which to conceptualize portals. It is the nonlinearity of internet-distributed television that enables-if not requires-this crucial point of distinction that produces markedly different industrial formations and audience practices. The nuance of understanding the key distinction of internet-distributed television as emerging from a technological affordance-but that this distinction is not technologically determined-illustrates the complexity of conceptualizing 
internet-distributed television and the interrelation among technologies, their affordances and limitations, and the industrial formations and audience practices accordingly encouraged and discouraged.

It is also necessary to acknowledge that the differentiation of internet-distributed television as of 2016 has as much to do with business model as technology-although this business model is in part made available by the affordances of internet distribution. Much of the thinking presented here focuses on the most commercially successful portals to date-namely Netflix and to an extent $\mathrm{HBO}^{3}$. Importantly, by relying solely on subscriber funding, these entities can hardly be compared with ad-supported television, regardless of distribution mechanism. Netflix is more unlike NBC because it is subscriber-funded than because it is internet-distributed. The prevalence of portals with subscriber-funded business models-such as Netflix, HBO Now, and DisneyLife-must be a central consideration, and given the limited space, the following discussion of strategies focuses on this context. Of course this is not to suggest that advertising-supported portals are unimportant, just to acknowledge the distinction of their enterprise that, at this point, provides less disruption of the industry.

The task of cultivating a library of content requires shifts in practices that developed for linear forms of television distribution and also requires shifts in strategies. Time constraints are embedded throughout the norms of linear television operation, not simply in scheduling. The scarcity of content led linear television industries to rely extensively on strategies such as windowing and exclusivity. The linear television industry is based on repeatedly selling the license to content so that a range of entities can schedule it to create audiences-typically to then sell them to advertisers within media operated according to a commercial mandate. The consent of viewers to abide by those windows of licensing was secured in large part by the impossibility—or significant technological challenge—of circumventing this set of relations.

The utility of windowing as a strategy now faces assault because of the intertwined shifts in audience expectations of convenience allowed by nonlinear access and the availability of distribution technologies that enable those behaviors. The central chal- 
lenge to windowing is not forcing viewers to wait, but to force them to watch at prescribed times. Viewers consume the abundance of content contained within portals without regard to time specificity. Instead, this organization encourages viewers to pursue self-determined viewing queues. The library derives value from the certainty of its holdings and from viewers being able to expect content ranked later in personal queues to still be available when they are prepared to view it, but windowing requires the availability of content for only a specified period of time.

Exclusivity was integrated with windowing as strategies for linear distribution, but exclusivity persists as a strategy in the nonlinear environment. Subscriber-funded portals increasingly rely on providing exclusive access to programs-especially those they develop. Exclusivity also works differently in this context. In the case of linear distribution, exclusivity was often secured for a period of time, typically corresponding to the window. Portals use exclusivity differently-again, particularly in relation to original content-as they seek to hold the exclusive license to content in perpetuity. Such licensing arrangements are most feasible in cases of vertical integration-for example, Amazon Studios as the creator for content distributed by Amazon. Within the norms of the broadcast paradigm viewers could wait for content to pass into a preferred window, but original portal content can remain exclusive to the portal indefinitely in a way that encourages some period of subscription. Such strategies begin to hint at the distinctions of producing a library.

Importantly, adjustments in the strategies of windowing and exclusivity produce consequences elsewhere in industrial practices-particularly in the nature of labor contracts and remuneration. Guilds and unions that represent creative talent working in television have struggled to keep pace with emerging distribution technologies and the practices they engender. Pay scales created in the linear era allowed above-the-line talent a meaningful revenue stake in products that were commercially successful by paying them residuals based on each airing of an episode through the many windows a good travelled, and these scales require radical restructuring for portals that hold licenses for an indefinite period. Notably this is an issue that affects both the licensing of goods originally created for linear services as well as content created for portals. The terms of payment for content created for portals are much different and lack significant residual remuneration for talent despite the 
long-term and potentially significant value of their work to the portal library. The common practices of portals to self-gather and retain data about the frequency of viewing allows only the portal any sense of the value created by each media good.

Obviously, industrial norms related to pay scales are likely to adjust as portals become a growing part of the television ecosystem. The point of their discussion here is as an illustration of the myriad adjustments produced by shifting from linear to nonlinear television distribution. Just as new industrial practices are created for the opportunities of nonlinear distribution and companies revise strategies to account for the adjusted conditions, these industrial norms exist in negotiation with audience practices that likewise evolve in accord with nonlinear distribution.

Importantly, portals compete for the attention of viewers not only on the basis of their programming, but also in relation to the experience of the portal-attributes that might be considered as characteristic of the use of the portal-the portal as a product-regardless of its programming. It remains very early days in the experience of nonlinear viewing. At this point, portal products are differentiated by log in processes and the options viewers encounter upon entering the portal. Some portals automatically begin playing content (autoplay)-illustrating an effort to reassert a "flow-like" linear experience. Some deployments of autoplay function as a form of recommendation, while others attempt convenience by playing the next episode or simply resuming content where a viewer left off. Further differentiation among portal products derives from the sophistication of recommendation and search mechanisms, the intuitiveness of content organization, and the ease of navigability. Many other aspects of audience experience derive from the content made available-a variable largely related to the licensing agreements portals make. For example, Netflix typically offers the full library of a series, except for the current season, while Hulu's holdings are typically the reverse. Netflix drew attention with its practice of simultaneous release of full seasons of new, original programming, while HBO Now abides by the linear release of its cable-distributed service.

Nonlinear distribution extricates timeliness from the industrial practices of television. Decades of familiarity with linear television distribution have led to elaborate and often deeply-entrenched expectations about the experience of watching 
television. Importantly, many of the behaviors long assumed inherent to television-linear television's protocols-have never been characteristic of the medium, but derive from its distribution system. Those born before 2000 may regard the experience of viewing content at a certain time, that one must wait a week between new episodes, or that advertisements are embedded at regular intervals as a "natural" experience of television. But such protocols result from a linear organization of television, and the array of practices emerging as characteristic of experiencing internet-distributed television are no more or less inherent to the medium.

An important next step in conceptualizing internet-distributed television is identifying other strategies or characteristics that distinguish portals. A clear indication that distribution technology must only be the start of conceptualizing internet-distributed television emerges from considering the range of strategies being deployed by portals. As noted earlier, variation among subscriber-funded and advertising-funded business models creates such different commercial contexts as to make consideration across business model of limited utility.

Although this analysis has emphasized nonlinearity as the defining affordance of internet-distributed television, it is the case that some portals employ a linear logic nevertheless. Typically isolated to portals that provide content that encourages live viewing - such as sporting events-some portals derive greater value from offering varied linear content. For example, sports portals enable viewers to select among various coterminous competitions, instead of only providing access to the one deemed most commercially valuable as typically chosen for broadcast or cable distribution.

Portals also differ based on the nature of their content. Netflix, Hulu, and Amazon offer long form, professionally produced series that have ample budgets and often require viewers to set aside leisure time to view. In contrast, a service such a YouTube-though of course a wide-ranging repository-features considerable short nuggets of professional content as well as extensive amateur and professional-aspiring content. The reliance on personality over production value in venues such as YouTube tends to correlate with lower production costs, and the shorter video lengths make it possible to integrate consumption of this video into the rhythms of daily life, part of what Ethan Tussey terms a "procrastination economy" (Tussey, 2013). 
Within the U.S., it seems as though two different industries of internet-distributed television may be emerging: one characteristic of the advertiser-supported video of YouTube and other multichannel networks (MCNs), and one that distributes content comparable to legacy television and relies on subscriber-funding. If this is the case, distinct understandings of the practices and norms of these industries must be developed instead of assuming the commonality of internet-distribution unites them.

Finally, just as media research developed elaborate theories about scheduling strategies of channels and networks over decades of investigation, so to must theories about the task of curating a portal and various curation strategies be created. At this nascent point of development, two continua of curation strategies are evident. One continuum illustrates a range of strategies related to the breadth or narrowness of a portal's library. Services such as Netflix and HBO offer relative breadth and relatedly rely on strategies connected with achieving scale. In contrast, several more narrowly-targeted portals also exist, though may not directly compete with these companies. Such niche portals offer particular programming - such as the comedy focus of SeeSo-or target particular audiences_-such as Noggin, a portal of programming for preschoolers. The breadth versus specificity of content offers different value propositions. Although niche-focus has been investigated in linear programming, the use of this strategy in a subscriber-funded context requires new assessments.

The second continuum spans portals with curation strategies aimed at gathering very specific content-regardless of license holder-and those that prioritize leveraging self-owned intellectual property. Although vertical integration was a key strategy of the television industry long before internet-distributed television, the emergent playing field has revealed some portals making this a core curation strategy. Assessing the role of content ownership and discerning whether owning ample content becomes a necessary attribute to compete in internet-distributed television are important considerations in understanding how legacy television may quickly come to dominate this new industry sector.

There is much theory building required and likely other key curation strategies. Importantly, different curation strategies are more or less useful relative to a portal's business model. As the competitive landscape of portals evolves, it will be 
crucial to identify how subscriber-funded and advertising-funded portals pursue discrepant curation strategies that match the differences in their core business proposition.

\section{Conclusions}

This is a knowingly preliminary assessment of internet-distributed television. This sector of the industry remains very nascent, as it has just been in the last eighteen months that the legacy television industry has openly pivoted its development and innovation efforts to this form of distribution. As José Álvarez Monzoncillo acknowledged in his 2011 assessment of internet television, at least a decade of experimentation awaits (Álvarez Monzoncillo, 2011, 10). The current range of ventures will yield a stasis of most viable practices, which will be derived from negotiation among the reconfigured practices attempted by industry and audience response to varied value propositions. Admittedly, this article but scratches the surface of an abundance of important questions about the creative implications and business practices that will result from internet-distributed television, but the consequences for norms of international flows of content and competition will be significant.

\section{Notes}

[1] To be clear, scarcity is a technological characteristic that was exacerbated in the U.S. by industry-influenced regulation that limited competition through the regulatory regime that allowed two VHF stations per market. From a technological standpoint, there could have been many more stations competing in a local market, though it is impossible to know the extent of competition the economics would have allowed. Likewise, the technological capacity of cable and satellite is treated with great simplicity here; although these services had broader capacity to offer many programming services, they were still bound to linear transmission. Throughout the 2000s, U.S. cable and satellite operators attempted increased nonlinear availability through the use of in home and cloud-based recording that would enable a video-on-demand experience. Although this technological solution was achieved, the core businesses and logics of these industries remain guided by-or set within a paradigm of-linear distribution. 
[2] At the risk of excessive detail, the transition to the DOCSIS (data over cable service interface specification) standard in the U.S. allowed cable providers the affordance of nonlinear distribution. Although this technological capacity exists and is used in "on demand" service, "cable" - as of 2016-remains more defined by linear distribution of content and related practices. At some point in the future, the distinction between cable and internet distributed television may become negligible due to cable's adoption of different industrial practices and related protocols.

[3] Though HBO Now has only been available in the U.S. for just over a year and cannot yet be identified as successful, HBO's deployment of the HBO Go portal in 2010 as a companion to its linear service and the fact that its linear business relies on a subscriber-funded model allow it to contribute meaningfully to this analysis.

\section{References}

Álvarez Monzoncillo, J. M. (2011) Watching the internet: The future of TV? Lisbon: Media XXI.

Bogost, I., \& Montfort, N. (2009) "Platform studies: Frequently asked questions," Digital Arts and Culture; nickm.com/if/bogost_montfort_dac_2009.pdf

Gitelman, L. (2006) Always already new: Media, history and the data of cultures. Cambridge: MIT Press.

Kuhn, T. (1962) The structure of scientific revolutions Chicago: University of Chicago Press.

Lotz, A. D. (2007). The television will be revolutionized. New York: New York University Press.

Lotz, A. D. (forthcoming) Being wired: How cable transformed television and the internet revolutionized it all.

Miége, B. (1989). The capitalization of cultural production. New York: International General.

Spigel, L. (2004) "Introduction." In L. Spigel and J. Olsson (Eds.), Television after TV: Essays on a medium in transition. Durham: Duke University Press.

Tussey, E. (2013) “Workspace media: The procrastination economy and the future of entertainment," PhD Dissertation, University of California, Santa Barbara. Williams, R. (1977) Marxism and literature. Glasgow: 0xford University Press. 